\title{
The Worcester water incident, UK: bias in self reported symptoms to an emergency helpline
}

\author{
David L Fone, Claire E Constantine, Brian McCloskey
}

Herefordshire Health Authority,Victoria House, Eign Street, Hereford HR4 0AN D L Fone

Worcester and District Health Authority, Worcester

C E Constantine

B McCloskey

Correspondence to: Dr Fone, Gwent Health Authority, Mamhilad House, Mamhilad Park Estate, Pontypool, NP4 0YP.

Accepted for publication 25 February 1998
In April 1994, chemical contamination of the River Severn affected the water supply to a population of 160000 in Worcestershire. ${ }^{1}$ During the incident the health authority free phone emergency helpline received 106 complaints of symptoms attributed to consumption of contaminated water. These complaints were important as they alerted the emergency incident team to the possibility of illness being associated with the chemical contamination, gave an early indication of the possible severity of illness, and also provisionally identified a register of cases.

However, identification of cases from those presenting to medical services or prompted from media interest during an infectious disease or chemical incident may result in a biased selection of the most severely affected or anxious. $^{23}$ Bias associated with self reported symptoms to an emergency helpline has not been previously reported. To investigate this possibility, we undertook a retrospective cohort study of complaints of symptoms to the helpline.

\section{Method}

Each complainant was sent a self completing questionnaire within a week of the incident, asking for demographic details, a checklist of 13 symptoms identified from complaints to the helpline, dates of onset and consumption of tap water during the incident.

The water company supplied distribution maps of areas supplied with contaminated water during the incident. Exposure was defined as consumption of contaminated water. For each individual symptom, the proportion of symptoms reported by exposed respondents with symptom onset during the incident was compared with the proportion of symptoms reported by non-exposed respondents using $\chi^{2}$ with Yates's correction or Fisher's exact test two tailed $\mathrm{p}$ value. Double data entry, validation, and analysis were performed using Epi-Info version $5 .^{4}$

Using prevalence data available from the population based retrospective cohort study ${ }^{1}$ carried out after the incident, differences in prevalence rates between complainants and non-complainants were compared for both exposed and non-exposed respondents for each individual symptom.

\section{Results}

Eighty nine (84\%) of the 106 complainants returned a completed questionnaire. Of these, $28(31 \%)$ were male (mean age 39.0 years) and $61(69 \%)$ were female (mean age 41.9 years, Kruskall-Wallis $=0.22, p=0.63)$. Nineteen respondents reported symptom onset pre-dating

Table 1 Comparison of symptom reporting between exposed and non-exposed complainants to the emergency helpline and population based study of exposed and non-exposed prevalence rates ${ }^{T}$

\begin{tabular}{|c|c|c|c|c|c|c|c|c|c|}
\hline \multirow[b]{3}{*}{ Symptom } & \multicolumn{5}{|l|}{ Helpline } & \multicolumn{4}{|c|}{ Population based study ${ }^{I}$} \\
\hline & \multirow{2}{*}{$\begin{array}{l}\text { Number (\%) of } \\
\text { respondents } \\
\text { reporting } \\
\text { symptom }(n=89) \\
(100 \%)\end{array}$} & \multirow{2}{*}{$\begin{array}{l}\text { Number (\%) of } \\
\text { exposed } \\
\text { respondents } \\
\text { reporting } \\
\text { symptom } \\
(n=45) \\
(100 \%)\end{array}$} & \multirow{2}{*}{$\begin{array}{l}\text { Number (\%) of } \\
\text { non-exposed } \\
\text { respondents } \\
\text { reporting } \\
\text { symptom } \\
(n=44) \\
(100 \%)\end{array}$} & \multirow{2}{*}{$\begin{array}{l}\chi^{2} \text { (Yates's } \\
\text { correction) }\end{array}$} & \multirow[b]{2}{*}{$p$ Value } & \multirow{2}{*}{$\begin{array}{l}\text { Number (\%) of } \\
\text { exposed } \\
\text { respondents } \\
\text { reporting } \\
\text { symptom } \\
(n=1380) \\
(100 \%)\end{array}$} & \multirow{2}{*}{$\begin{array}{l}\text { Number (\%) of } \\
\text { non-exposed } \\
\text { respondents } \\
\text { reporting } \\
\text { symptom } \\
(n=2361) \\
(100 \%)\end{array}$} & \multicolumn{2}{|c|}{$\begin{array}{l}\text { Absolute \% difference } \\
\text { between helpline and study } \\
\text { prevalence rates }\end{array}$} \\
\hline & & & & & & & & Exposed & Non-exposed \\
\hline Headache & $49(55)$ & $23(51.1)$ & $26(59.1)$ & 0.30 & 0.59 & $77(5.6)$ & $75(3.2)$ & 45.5 & 55.9 \\
\hline Abdominal pain & $45(51)$ & $22(48.9)$ & $23(52.3)$ & 0.01 & 0.91 & $82(5.9)$ & $72(3.1)$ & 42.9 & 49.2 \\
\hline Diarrhoea & $41(46)$ & $19(42.2)$ & $22(50.0)$ & 0.27 & 0.60 & $74(5.4)$ & $67(2.8)$ & 36.9 & 47.2 \\
\hline Nausea & $37(42)$ & $21(46.7)$ & $16(36.4)$ & 0.59 & 0.44 & $90(6.5)$ & $47(2.0)$ & 40.1 & 34.4 \\
\hline Lethargy & $37(42)$ & $18(40.0)$ & $19(43.2)$ & 0.01 & 0.93 & $57(4.1)$ & $60(2.5)$ & 35.9 & 40.6 \\
\hline Vomiting & $29(33)$ & $13(28.9)$ & $16(13.6)$ & 0.28 & 0.60 & $13(0.9)$ & $35(1.5)$ & 27.9 & 34.9 \\
\hline Dizziness & $20(22)$ & $11(24.4)$ & 9 (20.5) & 0.04 & 0.84 & $26(1.9)$ & $24(1.0)$ & 22.6 & 19.4 \\
\hline Shivers & $15(17)$ & $9(20.0)$ & $6(13.6)$ & 0.27 & 0.60 & $11(0.8)$ & $24(1.0)$ & 19.2 & 12.6 \\
\hline Sore throat & $13(15)$ & $6(13.3)$ & $7(15.9)$ & 0.00 & 0.96 & $51(3.7)$ & $12(0.5)$ & 9.6 & 15.4 \\
\hline Joint pains & $11(12)$ & $6(13.3)$ & $5(11.4)$ & 0.00 & 0.97 & $18(1.3)$ & $25(1.1)$ & 12.0 & 10.3 \\
\hline Skin irritation & $11(12)$ & $8(17.8)$ & $3(6.8)$ & 1.56 & 0.21 & $25(1.8)$ & $10(0.4)$ & 16.0 & 6.4 \\
\hline Itchy eyes & $7(8)$ & $3(6.7)$ & $4(9.1)$ & - & ${ }^{*} 0.71$ & $19(1.4)$ & $11(0.5)$ & 5.3 & 8.6 \\
\hline Sore mouth & $7(8)$ & $5(11.1)$ & $2(4.6)$ & - & ${ }^{*} 0.43$ & $19(1.4)$ & $12(0.5)$ & 9.7 & 4.0 \\
\hline
\end{tabular}

^Fisher's exact test. A variety of other symptoms including fever (two respondents), palpitations, back pain and blue tongue, feeling generally ill and loss of taste and smell with a feeling of soap in the nose (one respondent each) were also reported. 
the incident or did not state. Of the 70 respondents complaining of symptoms starting during the incident, $45(50.5 \%$ of the total 89 respondents) consumed contaminated water and were therefore exposed. There was no difference in the ratio of male:female between exposed (13:32) and non-exposed (15:29) respondents.

Table 1 shows the five most commonly reported symptoms were headache, abdominal pain, diarrhoea, nausea, and lethargy. There was no difference in the rate of reporting of each of the 13 symptoms between exposed and non-exposed respondents. Prevalence rates reported by both exposed and non-exposed helpline complainants were significantly increased compared with rates from the population based study, with marked differences in the degree of increase between exposed and non-exposed groups for each symptom.

\section{Discussion}

All 106 complainants to the helpline attributed their symptoms to consumption of water they believed to be contaminated, either because of noticing an unpleasant taste or odour or from media information. However, only 45 of the 89 respondents were actually exposed; nearly half of all initial complaints of symptoms could not therefore be attributable to consumption of contaminated water. Our study found no differences in rates of self reporting of symptoms between exposed and non-exposed respondents, suggesting that helplines are used by the "worried well" regardless of the incident or exposure for which they were established. Complainants to the helpline provided both an inflated estimate of the prevalence of each individual symptom and biased estimates of the risk of exposure, highlighting the difficulty in establishing unbiased case registers for long term follow up or case-control studies after acute environmental exposures.

Several sources of information bias were possible. ${ }^{5}$ Rumination and reporting bias may have resulted from the anxiety generated by the intense media coverage of incident and from the belief of exposure to contaminated water. Protopathic bias resulted from respondents reporting symptoms with date of onset before the incident. Information bias may be assessed at the analysis stage in case-control and cohort studies. For example, cases may be compared with controls at different levels of true exposure status from knowledge of water distribution, or control cohorts may be available who believe they were exposed from media information, but were unexposed in reality. Furthermore, adjustment for anxiety or the belief that symptoms were attributable to exposure may be made in multivariable analyses by including appropriate valid and reliable instruments in the study questionnaires, a methodology that requires further appraisal.

We should like to thank the helpline staff for their invaluable contribution during the major incident and the anonymous referees for their helpful comments.

Funding: Worcester and District Health Authority.

Conflicts of interests: none

1 Fowle SE, Constantine CE, Fone D, et al. An epidemiological study after a water contamination incident near Worcester, England in April 1994. F Epidemiol Community Health 1996;50:18-23.

2 Gunnell DJ. The public health physician's role in chemical incidents. F Public Health Med 1993;15:352-7.

3 Palmer SR. Epidemiology in search of infectious diseases: methods in outbreak investigation. $f$ Epidemiol Community Health 1989;43:311-4.

4 Dean AG, Dean JA, Burton AH, et al. Epi Info, Version 5: a word processing, database, and statistics programme for epidemiology on microcomputers. Georgia: USD Inc, 1990.

5 Sackett DL. Bias in analytic research. $\mathcal{F}$ Chronic Dis 1979;32:51-63. 